\title{
Selecting Various Industrial Competitors Affect the Risk Level of Viet Nam Stock Investment Industry
}

\author{
Dinh Tran Ngoc Huy* \\ International University of Japan, Japan \\ *Corresponding author: Dinh Tran Ngoc Huy, International University of Japan, Japan
}

Submission: April 11, 2018; Published: July 05, 2018

\begin{abstract}
Under a one factor model, this paperwork estimates the impacts of the size of firms' competitors in the stock investment industry on the market risk level, measured by equity and asset beta, of 6 listed companies in this category. This study identified that the risk dispersion level in this sample study could be minimized in case the competitor size kept as current approximate size (measured by equity beta var of 0,034 ).Beside, the empirical research findings show us that equity beta min value decreases from 0,247 to 0,244 when the size of competitor doubles.Last but not least, most of beta values are acceptable.
\end{abstract}

Ultimately, this paper illustrates calculated results that might give proper recommendations to relevant governments and institutions in reevaluating their policies during and after the financial crisis 2007-2011.

Keywords: Risk management; Competitive firm size; Market risk; Asset and equity beta; Stock investment

Jel Classification: G0; G3; G30

\section{Introduction}

Together with financial system development and the economic growth, throughout many recent years, Viet Nam stock investment industry is considered as one of active economic sectors, which has some positive effects for the economy. Additionally, financial risk and reactions has become an issue after the global crisis 2007-2009 which has some certain impacts on the whole Viet name economy, and specifically, the Viet Nam stock investment industry. Hence, this research paper analyzes market risk under a one factor model of these listed firms during this period [1].

This paper is organized as follow. The research issues and literature review will be covered in next sessions 2 and 3, for a short summary. Then, methodology and conceptual theories are introduced in session 4 and 5. Session 6 describes the data in empirical analysis. Session 7 presents empirical results and findings. Next, session 8 covers the analytical results. Then, session 9 presents risk analysis and session 10 covers discussion [2]. Session 11 will conclude with some policy suggestions. This paper also supports readers with references, exhibits and relevant web sources.

\section{Research issues}

For the estimating of impacts of a one factor model: the size of competitor on beta for listed stock investment industry companies in Viet Nam stock exchange, research issues will be mentioned as following:
Issue 1: Whether the risk level of stock investment industry firms under the different changing scenarios of the size of competitor increase or decrease so much.

Issue 2: Whether the disperse distribution of beta values become large in the different changing scenarios of the size of competitor in the stock investment industry.

\section{Literature Review}

William Sharpe (1963) pointed in a simplified model of portfolio theory that each stock is correlated with each other stock because all are correlated with "the market", and stock return depends on some factors such as a constant alpha and stock beta [3-8]. And Harry Markowitz developed diversification and modern portfolio theory using beta as one of key factors. Beta is used in CAPM model, which is developed by Jack Treyner, John Lintner, Jan Mossin and William Sharpe.

Black (1976) proposes the leverage effect to explain the negative correlation between equity returns and return volatilities. Diamond and Dybvig 1983 said banks can also help reduce liquidity risk and therefore enable long-term investment [1] also indicated in the three-factor model that "value" and "size" are significant components which can affect stock returns. They also mentioned that a stock's return not only depends on a market beta, but also on market capitalization beta. The market beta is used in the three 
factor model, developed by Fama and French, which is the successor to the CAPM model by Sharpe, Treynor and Lintner.

Next, Kim 2002 noted that the nature of competitive interaction in an industry is important in assessing the effect of corporate product strategies on shareholder value [9-13]. Pagan and Mao 2007 stated that An intermediated market can therefore remain viable in the face of competition from a possibly faster, non-intermediated market as long as the specialist can generate revenue for the above services that covers his/her costs associated with asymmetric information, order processing, and inventory management. Daly and Hanh Phan 2013 investigated the competitive structure of the banking industries in five emerging Asian countries including Viet Nam and showed that the global financial crisis affected dramatically the competition of banking system in emerging Asian countries. Last but not least, Ana and John 2013 Binomial LeveragVolatility theorem provides a precise link between leverage and volatility [14-16].

\section{Conceptual theories}

Determinants of equity and asset beta: Generally speaking, beta can be estimated for an individual firm by using regression. Beta is used in CAPM model, and it is a risk measure of a listed firm compared to the overall market risk. For example, if beta of a single listed firm equals to 2,5 it means that the firm risk is 2,5 times riskier than the overall risk of the market. Therefore, when an investor wants to make an investment in a financial market, beta is an overall risk measure in investing in a stock exchange market.

The impact of competition or the size of competitor on the economy and business: In a specific industry such as stock investment industry, there are many firms offering the similar products and services and this helps customers select a variety of qualified goods that meet their demand. Competitors could affect price and customer service policies; hence, affect revenues and profits of a typical company. The competition could drive down profits that firms can earn. Sources of competition include, but not limit to, training. Increasing training can help competition raising productivity. Two or more different firms offer various products or services to the same group of customer and the same need. This is called indirect competition.

\section{Methodology}

In this research, analytical research method is used, philosophical method is used and specially, scenario analysis method is used. Analytical data is from the situation of listed stock investment industry firms in VN stock exchange and applied current tax rate is $25 \%$. Finally, we use the results to suggest policy for both these enterprises, relevant organizations and government.

\section{General data analysis}

The research sample has total 6 listed firms in the stock investment industry market with the live data from the stock exchange. Firstly, we estimate equity and asset beta values of these firms, as well as the risk dispersion. Secondly, we change the competitor size from approximate size to doubling size and slightly smaller size to see the sensitivity of beta values [17-20]. We figure out that in 3 cases, asset beta mean values are estimated at 0,455, 0,421 and 0,423 which are decreasing more if the size of competitors doubles. Also in 3 scenarios, we find out equity beta mean values $(0,477,0,443$ and 0,442$)$ are also decreasing. Various competitors selected definitely have certain effects on asset and equity beta values (Table 1 ).

Table 1: The number of companies in research sample with different beta values and ratio.

\begin{tabular}{|c|c|c|c|c|c|c|}
\hline \multirow{2}{*}{ Equity Beta } & Current Size & \multirow{2}{*}{ Ratio } & Double Size & \multirow{2}{*}{ Ratio } & Smaller Size & \multirow{2}{*}{ Ratio } \\
\hline & No. of Firms & & No. of Firms & & No. of Firms & \\
\hline$<0$ & 0 & $0,0 \%$ & 0 & $0,0 \%$ & 0 & $0,0 \%$ \\
\hline $0<$ beta $<1$ & 6 & $100,0 \%$ & 6 & $100,0 \%$ & 6 & $100,0 \%$ \\
\hline Beta $>1$ & 0 & $0,0 \%$ & 0 & $0,0 \%$ & 0 & $0,0 \%$ \\
\hline total & 6 & $100,0 \%$ & 6 & $100,0 \%$ & 6 & $100,0 \%$ \\
\hline \multirow{2}{*}{ Asset Beta } & Current Size & \multirow{2}{*}{ Ratio } & Double Size & \multirow{2}{*}{ Ratio } & Smaller Size & \multirow{2}{*}{ Ratio } \\
\hline & No. of Firms & & No. of Firms & & No. of Firms & \\
\hline$<0$ & 0 & $0,0 \%$ & 0 & $0,0 \%$ & 0 & $0,0 \%$ \\
\hline $0<$ beta $<1$ & 6 & $100,0 \%$ & 6 & $100,0 \%$ & 6 & $100,0 \%$ \\
\hline Beta $>1$ & 0 & $0,0 \%$ & 0 & $0,0 \%$ & 0 & $0,0 \%$ \\
\hline total & 6 & $100,0 \%$ & 6 & $100,0 \%$ & 6 & $100,0 \%$ \\
\hline
\end{tabular}

\section{Empirical research findings and discussion}

Table 2: Analyzing market risk under three (3) scenarios.

\begin{tabular}{|c|c|}
\hline \multicolumn{2}{|c|}{ Fl as Current } \\
\hline Competitor size as current & Scenario 1 \\
\hline Competitor size slightly smaller & Scenario 2 \\
\hline Competitor size double & Scenario 3 \\
\hline
\end{tabular}

In the below section, data used are from total 6 listed stock investment industry companies on VN stock exchange (HOSE and HNX mainly). In the three scenarios, current financial leverage degree is kept as in the 2011 financial statements which is used to calculate market risk (beta) whereas competitor size is kept as current, then changed from double size to slightly smaller size. In short the below Table 2 shows three scenarios used for analyzing the risk level of these listed firms. 
Market risk (beta) under the impact of tax rate, includes:
A. Quity beta
B. Asset beta

Scenario 1: Current financial leverage and competitor size kept as current. In this case, beta values of 6 listed firms on VN stock investment industry market as: There are no listed firms with both equity and asset beta values $<0$ and there is no listed firms with equity beta values $>1$, or $0 \%$ of firms.

Scenario 2: Competitor size double, Beta values of total 6 listed firms on VN stock investment industry market as: There is no listed firms with both equity and asset beta values $<0$ and there is no listed firms with equity beta values $>1$, or $0 \%$ of firms. Competitor size increase has no change on the number of firms with equity beta value $>1$.

Scenario 3: Competitor size slightly smaller. Beta values of total 6 listed firms on the stock investment industry market in VN as: There are no listed firms with both equity and asset beta values $<0$ and there are no listed firms with equity beta values $>1$, or $0 \%$ of firms. Competitor size decrease has no change on the number of firms with equity beta value $>1$. All three above Tables 1-3 and data show that values of equity and asset beta in the three cases of changing competitor size have certain fluctuation.

\section{Comparing statistical results in 3 scenarios of changing leverage}

Based on the calculated results, we find out: First, Equity beta mean values in all 3 scenarios are acceptable $(<0,5)$ and asset beta mean values are also small $(<0,5)$. In the case of reported leverage in 2011 , equity beta max is 0,713 which are acceptable. If competitor size doubles, equity beta min reduces from 0,247 to 0,244 . Finally, when competitor size is slightly smaller, equity beta min goes up to the initial value of 0,247 (Tables 3-5).

Table 3: Statistical results (FL in case 1) (source: VN stock exchange 2012).

\begin{tabular}{|c|c|}
\hline Statistic Results & Equity Beta \\
\hline MAX & 0,713 \\
\hline MIN & 0,247 \\
\hline MEAN & 0,477 \\
\hline
\end{tabular}

Table 4: Statistical results (FL in case 2) (source: VN stock exchange 2012).

\begin{tabular}{|c|c|c|c|}
\hline Statistic Results & Equity Beta & Asset Beta (Assume Debt Beta=0) & Difference \\
\hline MAX & 0,713 & 0,704 & 0,0085 \\
\hline MIN & 0,244 & 0,213 & 0,0316 \\
\hline MEAN & 0,443 & 0,421 & 0,0217 \\
\hline VAR & 0,0433 & 0,0498 & $-0,0065$ \\
\hline Note: Sample size: 6 & & & \\
\hline
\end{tabular}

Table 5: Statistical results (FL in case 3) (source: VN stock exchange 2012).

\begin{tabular}{|c|c|c|c|}
\hline Statistic Results & Equity Beta & Asset Beta (Assume Debt Beta = 0) & Difference \\
\hline MAX & 0,713 & 0,704 & 0,0085 \\
\hline MIN & 0,247 & 0,186 & 0,0611 \\
\hline MEAN & 0,442 & 0,423 & 0,0194 \\
\hline VAR & 0,0429 & 0,0498 & $-0,0069$ \\
\hline \multicolumn{2}{|c|}{ Note: Sample size: 6} \\
\hline
\end{tabular}

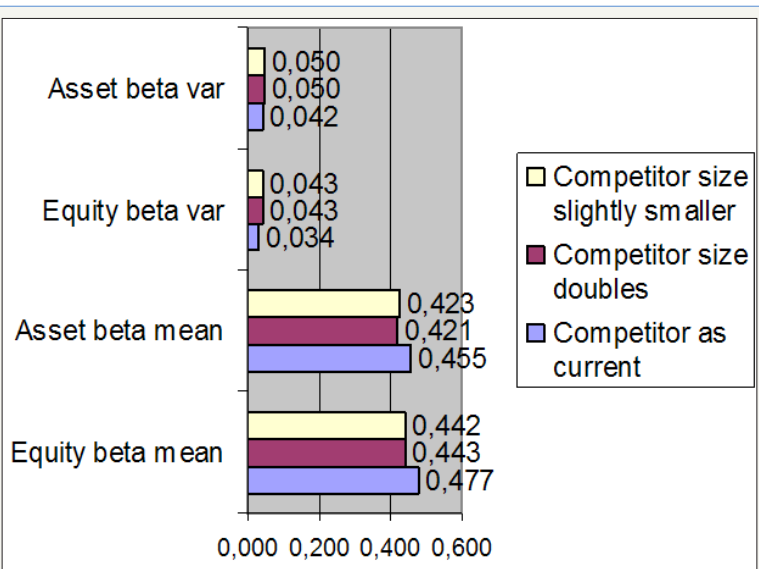

Figure 1: Comparing statistical results of equity beta variance and mean in three (3) scenarios of changing competitor size. 
The below Figure 1 shows us: when competitive firm size decreases slightly, average equity beta value decrease more $(0,442)$ compared to that at the initial selected competitor $(0,477)$. Next, average asset beta decreases little (to 0,423 ). However, in case the competitor size doubles, the risk level of the selected firms decreases little $(0,421)$. Last but not least, the fluctuation of equity beta value $(0,043)$ in the case of doubling size competitors is higher than $(>)$ the result in the current case. And we could note that in the case competitor size slightly smaller, the risk is little more dispersed $(0,05)$.

\section{Risk analysis}

Generally speaking, during the financial crisis 2007-2011, esp. the period 2007-2009, the investment and finance industry can survive well and maintain the development and profits, although these firms have to face other kinds of risks: materials or water or electric prices increasing. These risks can affect the operating cash flow of these companies.

\section{Discussion}

Table 1 shows us there are $100 \%$ of firms having acceptable beta values $(0<$ beta $<1)$ in cases: current or doubling size competitors. If competitor size is smaller, this number maintains at $100 \%$. Moreover, Figure 2 tells us that asset beta min increases to 0,213 in case doubling size competitors. Looking at exhibit 5, it is noted that comparing to beta results of electronic and electrical industry in the period 2007-2011, asset beta mean of stock investment industry group during 2007-2011 is higher in current situation $(0,455)$ and in the other 2 cases. And the risk dispersion in investment and finance industry when competitor size is smaller during 20072011 (shown by asset beta var of 0,05 ) is also smaller than that in electronic and electrical industries $(0,06)[21]$.

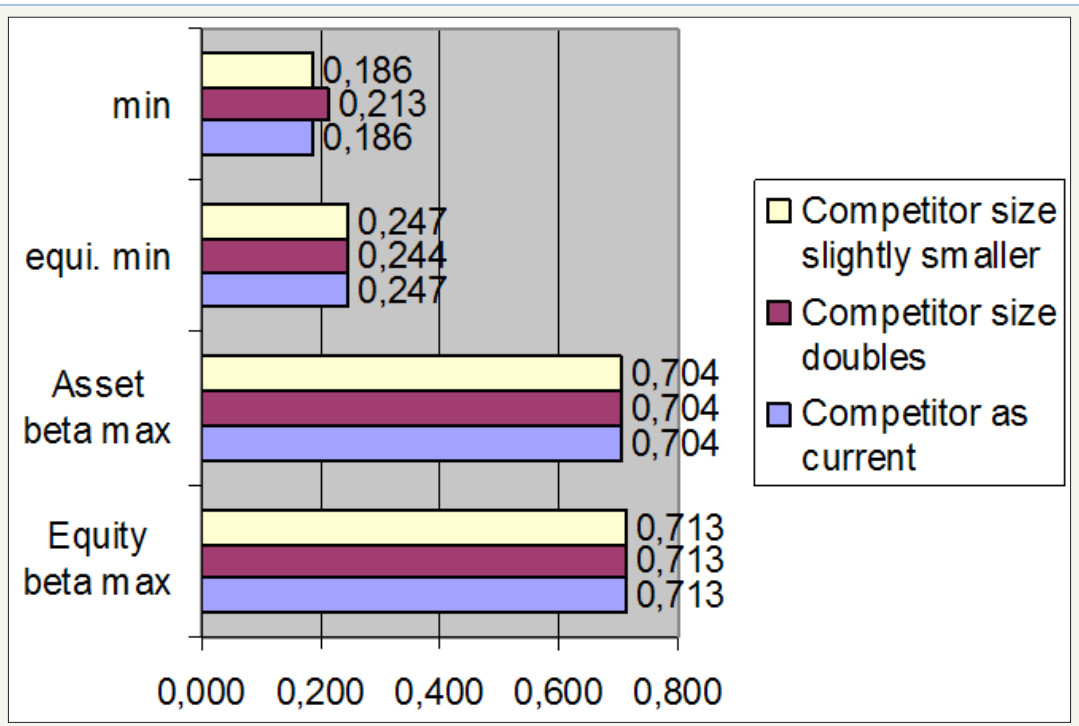

Figure 2: Comparing statistical results of equity/asset beta max and min in three (3) scenarios of changing competitor size.

\section{Conclusion and Policy Suggestion}

In conclusion, the government has to consider the impacts on the mobility of capital in the markets when it changes the macro policies and the legal system and regulation for developing the stock investment market. The Ministry of Finance continues to increase the effectiveness of fiscal policies and tax policies which are needed to combine with other macro policies at the same time [22]. The State Bank of Viet Nam continues to increase the effectiveness of capital providing channels for stock investment companies as we could note that in this study when competitive firm size doubles, the risk level decreases (asset beta mean value is estimated at: $0,421)$, and the equity beta var value $(0,043)$ is little higher than that in case competitor size as current $(0,034)$. Furthermore, the entire efforts among many different government bodies need to be coordinated [23]. Finally, this paper suggests implications for further research and policy suggestion for the Viet Nam government and relevant organizations, economists and investors from current market conditions.

\section{Acknowledgement}

I would like to take this opportunity to express my warm thanks to Board of Editors and Colleagues at Citibank -HCMC, SCB and BIDV-HCMC, Dr. Chen and Dr. Yu Hai-Chin at Chung Yuan Christian University for class lectures, also Dr Chet Borucki, Dr Jay and my exCorporate Governance sensei, Dr. Shingo Takahashi at International University of Japan. My sincere thanks are for the editorial office, for their work during my research. Also, my warm thanks are for Dr. Ngo Huong, Dr. Ho Dieu, Dr. Ly H. Anh, Dr Nguyen V. Phuc and my lecturers at Banking University - HCMC, Viet Nam for their help. Lastly, thank you very much for my family, colleagues, and brother in assisting convenient conditions for my research paper.

\section{References}

1. Eugene FF, Kenneth R (2004) The capital asset pricing model: theory and evidence. Journal of Economic Perspectives 18(3): 25-46.

2. Dexheimer J, Haugen C (2003) Sarbanes oxley: its impact on the venture capital community. Minnesota Journal of Business Law and Entrepreneurship 1. 
3. Fernandez P (2008) Levered and unlevered beta. SSRN working paper series, Elsevier, USA.

4. Flifel K (2012) Financial markets between efficiency and persistence: empirical evidence on daily data. Asian Journal of Finance and Accounting 4(2).

5. Gunaratha V (2013) The degree of financial leverage as a determinant of financial risk: an empirical study of Colombo stock exchange in Sri lanka. $2^{\text {nd }}$ International Conference on Management and Economics Paper, Sri Lanka.

6. Gao H, Harford J, Li K (2013) Determinants of corporate cash policy: insights from private firms. Journal of Financial Economics 109(3): 623639.

7. Huy, Dinh TN (2012) Estimating beta of Vietnam listed construction companies groups during the crisis. Journal of Integration and Development.

8. Jayant KR, Meneghetti C, Sharur H (2013) Contracting with non-financial stakeholders and corporate capital structure: the case of product warantties. Journal of Financial and Quantitative Analysis 48(3): 699727.

9. Litvak, Kate (2008) Defensive management: does the sarbanes-oxley act discourage corporate risk-taking? law and economics research Paper 108: 1-39.

10. Ling A (2013) Tax issues relating to intangibles. Asia-Pacific Tax Bulletin $19(2)$.
11. Wenling L, Whidbee DA (2013) Bank structure and failure. Journal of Financial Economic Policy, Emerald Insight, UK.

12. Mukerjee K (2013) Customer oriented organizations: a framework for innovation. Journal of Business Strategy 34(3): 49-56.

13. Pereiro LE (2010) The beta dilemma in emerging markets. Journal of Applied Corporate Finance 22(4): 110-122.

14. Shi M (2013) Capturing strategic competencies: cloud security as a case study. Journal of Business Strategy 34(3): 41-48.

15. Young L (2011) Market orientation processes. Australasian Marketing Journal Research, Australia.

16. Ang A, Chen J, (2007) CAPM over the long run: 1926-2001. Journal of Empirical Finance 14(1): 1-40.

17. Baker KH, Singleton CJ, Veit ET, (2011) Survey research in corporate finance: bridging the gap between theory and practice, Oxford University Press, USA.

18. (2010) ADB and Vietnam fact sheet. Vietnam, pp. 1-4.

19. http://www.mofa.gov.vn/vi

20. http://www.hsx.vn/hsx

21. www.tuoitre.com.vn

22. www.saigontimes.com.vn

23. www.mof.gov.vn (c) (i) Creative Commons Attribution 4.0

For possible submissions Click Here

\section{Submit Article}
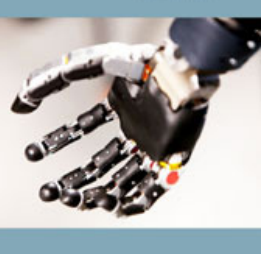

Significances of Bioengineering \& Biosciences

\section{Benefits of Publishing with us}

- High-level peer review and editorial services

- Freely accessible online immediately upon publication

- Authors retain the copyright to their work

- Licensing it under a Creative Commons license

- Visibility through different online platforms 